\title{
3 Research Square

\section{Evaluating the Antimicrobial Effect of Postbiotic Extract from Lactobacillus Casei on Escherichia Coli in Commercial Sterilized Milk}

\section{Samira Hosseini}

Tabriz University of Medical Science

Aziz Homayouni-Rad ( $\nabla$ homayuonia@tbzmed.ac.ir)

Tabriz University of Medical Science

Hossein Samadi Kafil

Tabriz University of Medical Science

Nazli Doroud

Tabriz University of Medical Science

\section{Research Article}

Keywords: Lactobacillus casei, Supernatant, Probiotics, Postbiotics, Pathogenic, E. coli

Posted Date: January 19th, 2022

DOI: https://doi.org/10.21203/rs.3.rs-1164061/v1

License: @ (i) This work is licensed under a Creative Commons Attribution 4.0 International License.

Read Full License 


\section{Abstract}

the antimicrobial effect postbiotics extant of Lactobacillus casei was evaluated against Escherichia coli by well propagation method and growth inhibition zone diameter was measured. The selected concentration of the postbiotic extract of Lactobacillus casei was added to milk containing E. coli, followed by evaluating the changes in colony number and $\mathrm{pH}$ during storage ( 1 and 5$)$ days. at a temperature of $4^{\circ} \mathrm{C}$ and compared with control milk. The largest growth inhibition zone was formed at a concentration of $800 \mu \mathrm{l} / \mathrm{ml}$ against $E$. coli. Also, the counts of E. coli decreased on days 1 and 5 in the evaluated milk containing postbiotic $(\mathrm{P} \leq 0.05)$. The $\mathrm{pH}$ of milk containing postbiotic was $6.5-6.8(\mathrm{P} \leq$ 0.05). The results showed that the postbiotics of $L$. casei inhibited the growth of $E$. coli in milk containing.

\section{Background}

For a first time the term probiotic was used in 1965 for a product excreted from one protozoan leading to the growth of another protozoan (1). Tissue extracts were also used for beneficial biological interactions, including the promotion of microbial growth. In 1974, Parker was the first to identify probiotics as useful dietary supplements, leading to the production of healthy intestinal microbiota (2). Previous studies have provided some plausible evidence for several favorable mechanisms that have intestinal-enhancing effects (3). These include the term intestinal microbiota, continuous competition between the mucosa and the epithelium, functional improvement of the epithelial cell epithelial barrier, and modulation of the immune system (4). However, recent evidence suggests that the probiotic survival factors may not be necessary to achieve its health-enhancing effects, and biological compounds derived from it such as cell bodies, cell extracts, pure cell walls, and supernatants can have the same health effects and play a role through similar or different metabolic pathways (5). In this regard, a study measured the ratio of live and non-living cells of probiotic supplements, indicating that the population of non-living cells was significantly higher than living cells (6). Thus, a major part of the health effects of probiotic supplements could be related to the presence of non-living cells (Postbiotics) created during the production and maintenance of the product (7). Hence, biological compounds such as postbiotics with unique properties such as stability, non-toxicity, and safety can be introduced as an alternative to probiotics (8). The production of postbiotics usually involves cell degradation techniques such as heat and enzymatic treatments, solvent extraction, and sonication. Several steps such as extraction, centrifugation, dialysis, and freeze-drying are also used to increase the production efficiency and storage of these compounds (9). Postbiotics consist of inactivated microbial cells, including cell bodies, cell fissures (teichoic acid, peptidoglycan-derived meso peptides, cell surface proteins, and end monopoly saccharides)(10), as well as cellular metabolites (short-chain fatty acids, enzymes) (11). Organic acids are released when microbial cells are alive or broken down in the host's intestinal tract and have health-promoting effects on the host if taken in enough amounts (12). In recent years, many scientific studies have reported the health effects of supplements containing postbiotics, while illuminating the precise functional mechanisms associated with probiotic strains, including Lactobacillus casei and piracies, which are cellular (13). Inactivated cells have different functional properties such as antimicrobial, antioxidant, and immune-modulating effects 
and are applicable in various types of pharmaceutical and food systems to achieve the goals of promoting host health (14). The protective effect of $L$. casei on the preservation of fermented foods is due to the acidic conditions that occur during the growth of bacteria in food (15). Conversion of carbohydrates to organic acids such as acetic acid, and lactic acid, along with lowering the $\mathrm{pH}$, increases the shelf life and good quality of fermented foods (16). This bacterium can produce other substances such as bacitracin, hydrogen peroxide, dactyl, acetaldehyde, ammonia, and free fatty acids and inhibit the growth of many microorganisms $(10,17)$. They can be used as medicine if the necessary principles are observed. Because the function of $L$. casei-derived postbiotics does not depend on cell viability, their purified bacteriocins are used as biological preservatives, resulting in the longer shelf life of dairy products and food safety (18). They also have antihypertensive, antimicrobial, and immune-boosting properties by producing active peptides in dairy products. The postbiotic derivative of $L$. casei can produce various metabolites, such as lactic acid, hydrogen peroxide, bacteriocins, dactyl, and acetone, and prevent the growth of rival bacteria, including foodborne pathogens like $E$. coli (19). Hydrogen peroxide can damage bacterial nucleic acids by increasing membrane permeability (20). Studies have shown that bacteriocins are important in preserving dairy products, including long shelf life, protection at a temperature of $\angle 4^{\circ} \mathrm{C}$, and better preservation of nutrients and vitamins (21). Also, there is now consumer pressure to reduce artificial substances and additives in foods (22). The demand for processed and fresh foods can be met in part by the use of bacteriocins because their protein compounds reduce natural antimicrobial activities by enzymatic activity(10). They can also produce enzymes due to their very high thermal stability and denaturation resistance (23). In this regard this study aims to evaluate the antimicrobial effect of postbiotic extract derived from L. casei on E. coli in commercial sterilized milk.

\section{Materials And Methods}

\subsection{Bacteria Preparation and Usage}

L. casei ATCC $=39392$ and E. coli ATCC $=25922$ were prepared from the Scientific and Industrial Research Organization (Tehran, Iran) and activated according to this protocoles.

\subsection{Postbiotic Extract Production Process (Supernatant)}

L. casei were cultured in MRS-broth and incubated in the temperature of $37 \pm 1^{\circ} \mathrm{C}$ for $48 \mathrm{hr}$ in a $\mathrm{CO}_{2}$ incubator. the grown bacteria were poured into a falcon and centrifuged for $20 \mathrm{~min}$ at $10000 \mathrm{rpm}$ at a temperature of $4^{\circ} \mathrm{C}$ to detach the postbiotics from the cells. After separating the supernatant and measuring the $\mathrm{pH}$, the supernatant was placed in the dry freezer $-40^{\circ} \mathrm{C}$ for $24 \mathrm{hr}$ to get its lyophilized form. Then, the resulting lyophilized powder was stored at $-80^{\circ} \mathrm{C}$ until use.

\subsection{Method for the Evaluation of the Antimicrobial Properties of Postbiotic Extracts}

\subsubsection{Standardize microorganisms}


Microorganisms were standardized with 0.5 Mc Farland standard. 0.5 Mc Farland shows a cell density of $1.5 \times 10^{8} \mathrm{CFU} / \mathrm{ml}$.

\subsection{2. (AWD) Method}

For evaluate antimicrobial activity of postbiotic extract (supernatant), E. coli strain was cultured by the surface culture method under standard conditions of $0.5 \mathrm{Mc}$ Farland suspension. Wells were drilled on Müller Hinton agar medium with a diameter of and $4 \mathrm{~mm}$ depth using pipette number 5 . Different concentrations of postbiotic extract (supernatant) were poured into the wells and incubated at $37^{\circ} \mathrm{C}$ for 24 hours. The cycle appeared around the wells after the specified time and temperatures and it is diameter was measured. The diameter of the halo indicates the antimicrobial effect of the extract. The larger the halo, the more antimicrobial effects the extract will have. Diameter of the growth inhibition halo was measured by a caliper and reported in millimeters to determine the antimicrobial effect.

\subsection{Inoculation of Postbiotic Extracts and Microbial Species in Milk}

First, $400 \mathrm{ml}$ of sterilized milk was poured into a sterile Erlenmeyer flask and used as a control sample. Then, only $E$. coli was added at a concentration of $1 / 5 \times 10^{8}$ and homogenized, followed by pouring another $400 \mathrm{ml}$ of sterilized milk to another Erlenmeyer flask and testing as a sample. Both samples were incubated for 10 hours and then cooled to $4-5^{\circ} \mathrm{C}$ and refrigerated.

\subsubsection{Microbiologic Assays}

The antimicrobial maintainer effective test was used to determine the antimicrobial activity of the postbiotic supernatant. The challenge microorganism was derived from the collection of the original stock cultures $E$. Coli. the suspension was ready conforming to standardized methods to come to a proximate concentration of $1 / 5 \times 10^{8}$ (CFU) per milliliter serial. Dilutions of one $\mathrm{ml}$ of the tested and control samples in $9 \mathrm{ml}$ of 0.9 saline and dilutions up to $1 \times 10^{-10} \mathrm{CFU} / \mathrm{mL}$ were prepared from the sample. Then $0.1 \mathrm{ml}$ of each dilution in three replications was transferred to disposable plates containing EMB culture medium to perform a surface culture. Incubation was performed at $37^{\circ} \mathrm{C}$ for 24 hours, followed by counting the colonies. The population of $E$. coli in the inoculated sample and negative control was determined on days 1 and 5 using the pour-plate method.

\subsubsection{Determining the $\mathrm{pH}$}

The samples' pH was measured to the national standard of Iran (ISIRI No. 2852) using a pH-meter on days 1 and 5. First, the $\mathrm{pH}$ meter was calibrated. $\mathrm{pH} 4$ and 7. The $\mathrm{pH}$-meter electrode was placed inside the sample for at least 45 seconds after adjusting and rinsing the electrode with distilled water and final drying. Ultimately, the $\mathrm{pH}$ of the sample (in three replications) was reported.

\subsection{Statistical Analysis}


All experiments were conducted in triplicate. The data were reported as Mean \pm Standard Deviation for the measurements of prohibition zones in the antimicrobial activity tests, and one-way (ANOVA) was used to compare the mean values $(P \leq 0.05)$.

\section{Results}

\subsection{Antimicrobial Activity}

Plates containing Müller Hinton agar were prepared to test antimicrobial activity. The wells were then drilled at a distance of three millimeters and filled with postbiotic extract (supernatant) at concentrations of $800,600,400,200$, and $0 \mu \mathrm{l} / \mathrm{ml}$. A normal halo grew and appeared after incubation for 24 hours. The diameters of non-growth halos against $E$. coli were 36, 27, 35, 29, and $0 \mathrm{~mm}$ (Fig. 1). According to the chart, the greatest inhibitory concentration of the postbiotic extract of $L$. casei for $E$. coli was $800 \mathrm{mg} / \mathrm{ml}$.

According to the results of the analysis of variance at a significance level of $95 \%$, with increasing the concentration of the extract (supernatant), the diameter of the growth inhibition zone also increased ( $\mathrm{P} \leq$ 0.05). (Table 1)

Table 1

Analysis of variance to evaluate the antimicrobial properties of different levels of postbiotic extract against $E$. coli by well method.

\begin{tabular}{|lllll|}
\hline P-Value & F-Value & MC & df & Source \\
\hline$\leq 0.05$ & 22.36 & 176.6 & 1 & The amount of extract to bacteria \\
\hline- & - & 48.01 & 1 & Coefficient of variation (CV) \\
\hline
\end{tabular}

\subsection{Variation in the Number of Bacteria in Milk Samples During refutation}

In this study, $800 \mathrm{mg} / \mathrm{ml}$ of the postbiotic extract was studied against $E$. coli in milk samples during days 1 and 5 . Hence, one milliliter of each dilution in three replications was transferred to disposable plates with the specific culture medium of E. coli EMB after preparing successive dilutions by the surface method. The plate containing the bacterial sample was incubated at $37^{\circ} \mathrm{C}$ for 24 hours. (Table 2)

Table 2

Analysis of variance of $E$. coli count in milk with and without postbiotic.

\begin{tabular}{|lllll|}
\hline P-Value & F-Value & MC & df & Source \\
\hline$\leq 0.05$ & 2832.17 & 2.30 & 1 & Postbiotic \\
$\leq 0.05$ & 115.64 & 9.39 & 1 & Day \\
$\leq 0.05$ & 117.61 & 9.54 & 1 & Postbiotic $\times$ Day \\
\hline
\end{tabular}


milk samples containing postbiotic extract (supernatant) from L. casei had the lowest number of $E$. coli compared to the control sample ( $\mathrm{P} \leq 0.05$ ). (Fig. 2). Milk containing postbiotic extract of $L$. casei inhibited the growth of $E$. coli in the first and the fifth days. However, in postbiotic-free milk extract, the number of $E$. coli increased in both the first and the fifth days. The growth of $E$. coli in each milk sample in the first and the fifth days was shown at Table 3 . The population of $E$. coli in milk samples containing postbiotic extract decreased at a temperature of $4^{\circ} \mathrm{C}$ compared to the control sample $(P \leq 0.05)$.

Table 3

Mean, standard deviation, and standard error of the number of $E$. coli in the studied crops $(\mathrm{CFU} / \mathrm{ml})$, number of replicates: N, a, b, c.: In each column, the difference between the means without common letters is significant, and the difference between the means with common letters is insignificant.

\begin{tabular}{|c|c|c|c|c|c|c|c|c|}
\hline \multirow[b]{2}{*}{$\begin{array}{l}\text { Type of } \\
\text { cultivation }\end{array}$} & \multicolumn{4}{|c|}{$\begin{array}{l}\text { Day } 1 \\
\text { (CFU/mL) }\end{array}$} & \multicolumn{4}{|c|}{$\begin{array}{l}\text { Day } 5 \\
\text { (CFU/mL) }\end{array}$} \\
\hline & $\mathbf{N}$ & Mean & SD & SE & $\mathbf{N}$ & Mean & SD & SE \\
\hline E. coli & 10 & $97.36 \times 10^{6}$ & $\begin{array}{l}3.4 \times 10^{6} \\
a\end{array}$ & $1.78 \times 10^{6}$ & 10 & $\begin{array}{l}116 \times 10^{8} \\
a\end{array}$ & $5.9 \times 18^{8}$ & $3.8 \times 10^{8}$ \\
\hline $\begin{array}{l}\text { E. coli }+ \\
\text { Postbiotic }\end{array}$ & 10 & $66.70 \times 10^{6}$ & $0.127^{a}$ & 0.052 & 10 & $\begin{array}{l}17.2 \times 10^{8} \\
b\end{array}$ & $0.39 \times 10^{8}$ & $0.16 \times 10^{8}$ \\
\hline
\end{tabular}

The mean number of living $E$. coli cells in the milk sample containing postbiotic extract was on days 1 and 5 respectively.

\section{3. pH Variation in Milk Samples During storage}

The $\mathrm{pH}$ of all milk samples containing $800 \mu \mathrm{l} / \mathrm{ml}$ postbiotic and samples without postbiotics was evaluated on days 1 and 5 . The experiment was factorial in a randomized complete block design with three replications (Table 4). Based on the results samples of milk containing postbiotic extract (supernatant) and control samples, had a significant difference on days 5 and 1 ( $P \leq 0.05$ ). (Fig. 3, and Table 5). on the first day showed that the $\mathrm{pH}$ of the sample without postbiotic was lower than the sample containing postbiotic. This comparison on day 5 showed that the sample without postbiotic had the lowest $\mathrm{pH}$ value compared to the sample containing postbiotic. In general, based on the obtained results, the $\mathrm{pH}$ of the sample containing postbiotic was $1(\mathrm{P} \leq 0.05)$, which showed the growth inhibitory effect on E. coli. Although (Escherichia coli) is able to grow in a neutral $\mathrm{pH}$ medium, in this study, the presence of postbiotic have prevented the growth of this bacterium in a neutral medium. During the first and the fifth days, the $\mathrm{pH}$ of milk containing postbiotic extract (supernatant) did not decrease, indicating the effect of postbiotic and inhibition of $E$. coli growth. In general, there was a significant difference between the control sample and the postbiotic sample in the present study $(P \leq 0.05)$. 
Table 4

Analysis of $\mathrm{pH}$ variance of milk with and without postbiotics against E. coli.

\begin{tabular}{|lllll|}
\hline P-Value & F-Value & MC & df & Source \\
\hline$\leq 0.05$ & 38.640 & 41.22 & 1 & Postbiotic \\
$\leq 0.05$ & 67.4 & 16.0 & 1 & Day \\
$\leq 0.05$ & 42 & 47.1 & 1 & Postbiotic $\times$ Day \\
\hline
\end{tabular}

Table 5

Mean, standard deviation, and standard in $\mathrm{pH}$ assessment, number of replicates: $\mathrm{N}, \mathrm{a}, \mathrm{b}, \mathrm{c} .:$ In each column, the difference between the means without common letters is significant, and the difference between the means with common letters is insignificant.

\begin{tabular}{|c|c|c|c|c|c|c|c|c|}
\hline \multirow[b]{2}{*}{ Type of cultivation } & \multicolumn{4}{|c|}{$\begin{array}{l}\text { Day } 1 \\
\text { (CFU/mL) }\end{array}$} & \multicolumn{4}{|c|}{$\begin{array}{l}\text { Day } 5 \\
\text { (CFU/mL) }\end{array}$} \\
\hline & $\mathbf{N}$ & Mean & SD & SE & $\mathbf{N}$ & Mean & SD & SE \\
\hline E. coli & 10 & 5.015 & $0.088^{a}$ & 0.036 & 10 & $4.877^{a}$ & 0.088 & 0.036 \\
\hline E. coli + Postbiotic & 10 & 4.009 & $0.127^{a}$ & 0.052 & 10 & $4.552^{a b c}$ & 0.302 & 0.123 \\
\hline
\end{tabular}

\section{Discussion}

In recent decades, bioactive compounds such as probiotics, prebiotics, and postbiotics have attracted much attention. These compounds are related to the beneficial gut microbiota and promote the health of the host (24). Postbiotics are also functional parts of living probiotics that have the ability to perform the biological and physiological functions of their living parent cells $(25,26)$. Postbiotics usually exert their health and therapeutic effects through similar or different mechanisms of action from their parent cells (27).. Postbiotics are less sensitive than probiotics to processing conditions, environmental factors, and gastrointestinal conditions, which adds to their economic viability (28). E. coli is one of the most common causes of food infection. It is also a common pathogenic bacterium between humans and animals and one of the most important bacterial agents transmitted from food (29). Because this bacterium has become resistant to antibiotic treatment, non-antibiotic antimicrobial methods such as probiotics and post-antibiotics are of great interest (30). The antimicrobial effect of $L$. casei supernatant can be attributed to the production of lactic acid because the environment becomes acidic during its growth, and pathogenic bacteria are sensitive to acidic conditions and are killed in low acidity (31).

According to the results, different concentrations of postbiotic extract (supernatant) influenced the growth of E. coli. The study showed that higher concentrations of postbiotic extract (supernatant) led to a larger diameter of the growth inhibition zone (32). reported that the smallest inhibitory concentrations of L. casei supernatant, cell wall, and cytoplasmic extract of $L$. casei had the greatest antimicrobial impacts on E. coli with gastrointestinal infections (33). This study reported that the various concentrations of the 
postbiotic extract had inhibitory effect on the growth of E. coli. The findings are consistent with a 2020 study by Mantziari et al. examined the antimicrobial effects of Lactobacillus species on E. coli (34), and based on the results, the evaluation of the antimicrobial properties of the postbiotic extract (supernatant) against $E$. coli was confirmed (35). Thus, the extraction and use of postbiotics, both in the laboratory and in the food industry, can prevent the growth of pathogenic microbes, increases the shelf life, and delays the spoilage of food products (36).

In this study, milk was selected as the base food medium in which the postbiotic extract (supernatant) of L. casei was added. The results indicated that the presence of postbiotic at a concentration of $800 \mu \mathrm{l} / \mathrm{ml}$ inhibited the growth of $E$. coli in commercial sterile milk. This finding is consistent with the results of Karimi et al (37), who introduced mechanisms related to the inhibitory effect of Lactobacilli by producing short-chain active fatty acids as well as consuming nutrients and bacitracin's in may suppress the pathogenic bacteria dairy products(38). It was also reported in this study that higher concentrations of postbiotic extract (supernatant) of $L$. casei in milk led to a longer shelf life at refrigerator temperature.

Based on the results, the $\mathrm{pH}$ in the control milk sample without postbiotic and with only $E$. coli decreased to 3.8 on the fifth day. In contrast, in the tested milk sample containing postbiotic, the $\mathrm{pH}$ remained around 7.2. In other words, the pH of milk samples containing postbiotics and E. coli was about 6.5-7.2 until fifth days, which was significantly higher than the $\mathrm{pH}$ of the milk sample without postbiotic that was

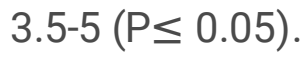

According to the results obtained from the antimicrobial properties of postbiotic extract (supernatant) at a concentration of $800 \mu \mathrm{l} / \mathrm{ml}$ in milk containing E. coli, the hypothesis regarding the addition of postbiotic extract (supernatant) to milk against $E$. coli was confirmed. Therefore, the use of postbiotic products in the food industry can prevent and lead to long-term storage of milk.

\section{Declarations}

\section{Ethics approval and consent to participate}

To carry out this study, all methods were carried out in accordance with relevant guidelines and regulations. The Ethics Committee of Tabriz University of Medical Science, Tabriz approved this study (IR.TBZMED.VCR. REC.1398.393).

\section{Consent for publication}

Not applicable.

\section{Availability of data and materials}

The datasets generated and analyzed in this study are not publicly available due to the data sensitivity and the data use agreement condition of the medical record data. However, the data can be sent and are available from the corresponding author of the paper on reasonable requests. 


\section{Competing interests}

The authors declare that they have no competing interests.

\section{Funding}

This study has been conducted in Partial Fulfillment of the Requirements for the Degree of Master of Food hygiene and safety, Faculty of Graduate Studies, Tabriz University of Medical Science, Funding was provided by the University of Medical Science (Grant no. 63726).

\section{Authors' contributions}

All authors listed have contributed to the work and approved it for publication. The authors have worked in an organized manner. Samira Hosseini has supervised the work, communicated with the key persons, and wrote the manuscript. Aziz Homayouni Rad has designed the study, collected the data, and did the statistical analysis. Hossein Samadi Kafil and Nazli Doroud have reviewed the data and the final manuscript for approval. The author(s) read and approved the final manuscript.

\section{Acknowledgments}

The authors would like to express their thanks to the Research vice-chancellor of Tabriz University of Medical Sciences for financial support of this study.

\section{References}

1. Wickens KL, Barthow CA, Murphy R, Abels PR, Maude RM, Stone PR, et al. Early pregnancy probiotic supplementation with Lactobacillus rhamnosus HN001 may reduce the prevalence of gestational diabetes mellitus: a randomised controlled trial. British Journal of Nutrition. 2017;117(6):804-13.

2. Castro-González JM, Castro P, Sandoval H, Castro-Sandoval D. Probiotic lactobacilli precautions. Frontiers in microbiology. 2019;10:375.

3. Sanders ME, Merenstein DJ, Reid G, Gibson GR, Rastall RA. Probiotics and prebiotics in intestinal health and disease: from biology to the clinic. Nature reviews Gastroenterology \& hepatology. 2019;16(10):605-16.

4. Fung TC. The microbiota-immune axis as a central mediator of gut-brain communication. Neurobiology of disease. 2020;136:104714.

5. Azad M, Kalam A, Sarker M, Li T, Yin J. Probiotic species in the modulation of gut microbiota: an overview. BioMed research international. 2018;2018.

6. Sánchez B, Delgado S, Blanco-Míguez A, Lourenço A, Gueimonde M, Margolles A. Probiotics, gut microbiota, and their influence on host health and disease. Molecular nutrition \& food research. 2017;61(1):1600240. 
7. Żółkiewicz J, Marzec A, Ruszczyński M, Feleszko W. Postbiotics-a step beyond pre-and probiotics. Nutrients. 2020;12(8):2189.

8. Mora-Sánchez B, Balcázar JL, Pérez-Sánchez T. Effect of a novel postbiotic containing lactic acid bacteria on the intestinal microbiota and disease resistance of rainbow trout (Oncorhynchus mykiss). Biotechnology Letters. 2020;42:1957-62.

9. Chaluvadi S, Hotchkiss AT, Yam KL. Gut microbiota: Impact of probiotics, prebiotics, synbiotics, pharmabiotics, and postbiotics on human health. Probiotics, Prebiotics, and Synbiotics: Bioactive Foods in Health Promotion: Elsevier Inc.; 2015. p. 515-23.

10. Rad AH, Hosseini S, Pourjafar H. Postbiotics as Dynamic Biological Molecules for Antimicrobial Activity: A Mini-Review.

11. Chuah L-O, Foo HL, Loh TC, Alitheen NBM, Yeap SK, Mutalib NEA, et al. Postbiotic metabolites produced by Lactobacillus plantarum strains exert selective cytotoxicity effects on cancer cells. BMC complementary and alternative medicine. 2019;19(1):1-12.

12. Vallianou N, Stratigou T, Christodoulatos GS, Tsigalou C, Dalamaga M. Probiotics, prebiotics, synbiotics, postbiotics, and obesity: current evidence, controversies, and perspectives. Current obesity reports. 2020:1-14.

13. Homayouni Rad A, Aghebati Maleki L, Samadi Kafil H, Abbasi A. Postbiotics: A novel strategy in food allergy treatment. Critical reviews in food science and nutrition. 2021;61(3):492-9.

14. Homayouni Rad A, Samadi Kafil H, Fathi Zavoshti H, Shahbazi N, Abbasi A. Therapeutically effects of functional postbiotic foods. Clinical Excellence. 2020;10(2):33-52.

15. Abbasi A, Aghebati-Maleki L, Homayouni-Rad A. The promising biological role of postbiotics derived from probiotic Lactobacillus species in reproductive health. Critical Reviews in Food Science and Nutrition. 2021:1-13.

16. Rad AH, Aghebati-Maleki L, Kafil HS, Abbasi A. Molecular mechanisms of postbiotics in colorectal cancer prevention and treatment. Critical reviews in food science and nutrition. 2021;61(11):1787803.

17. Compare D, Rocco A, Coccoli P, Angrisani D, Sgamato C, lovine B, et al. Lactobacillus casei DG and its postbiotic reduce the inflammatory mucosal response: an ex-vivo organ culture model of postinfectious irritable bowel syndrome. BMC gastroenterology. 2017;17(1):1-8.

18. Osman A, El-Gazzar N, Almanaa TN, El-Hadary A, Sitohy M. Lipolytic Postbiotic from Lactobacillus paracasei Manages Metabolic Syndrome in Albino Wistar Rats. Molecules. 2021;26(2):472.

19. Behbahani BA, Noshad M, Falah F. Inhibition of Escherichia coli adhesion to human intestinal Caco-2 cells by probiotic candidate Lactobacillus plantarum strain L15. Microbial pathogenesis. 2019;136:103677.

20. Tsilingiri K, Barbosa T, Penna G, Caprioli F, Sonzogni A, Viale G, et al. Probiotic and postbiotic activity in health and disease: comparison on a novel polarised ex-vivo organ culture model. Gut. 2012;61(7):1007-15. 
21. Falah F, Vasiee A, Behbahani BA, Yazdi FT, Moradi S, Mortazavi SA, et al. Evaluation of adherence and anti-infective properties of probiotic Lactobacillus fermentum strain 4-17 against Escherichia coli causing urinary tract infection in humans. Microbial pathogenesis. 2019;131:246-53.

22. Collado M, Vinderola G, Salminen S. Postbiotics: Facts and open questions. A position paper on the need for a consensus definition. Beneficial microbes. 2019;10(7):711-9.

23. Rad AH, Aghebati-Maleki L, Kafil HS, Gilani N, Abbasi A, Khani N. Postbiotics, as dynamic biomolecules, and their promising role in promoting food safety. 2021.

24. Chang HM, Foo HL, Loh TC, Lim ETC, Mutalib NEA. Comparative Studies of Inhibitory and Antioxidant Activities, and Organic Acids Compositions of Postbiotics Produced by Probiotic Lactiplantibacillus plantarum Strains Isolated From Malaysian Foods. Frontiers in veterinary science. 2020;7.

25. Izuddin WI, Humam AM, Loh TC, Foo HL, Samsudin AA. Dietary postbiotic Lactobacillus plantarum improves serum and ruminal antioxidant activity and upregulates hepatic antioxidant enzymes and ruminal barrier function in post-weaning lambs. Antioxidants. 2020;9(3):250.

26. Rinaldi F, Trink A, Pinto D. Efficacy of postbiotics in a PRP-like cosmetic product for the treatment of alopecia area Celsi: a randomized double-blinded parallel-group study. Dermatology and therapy. 2020;10(3):483-93.

27. Geraldo BM, Batalha MN, Milhan NV, Rossoni RD, Scorzoni L, Anbinder AL. Heat-killed Lactobacillus reuteri and cell-free culture supernatant have similar effects to viable probiotics during interaction with Porphyromonas gingivalis. Journal of periodontal research. 2020;55(2):215-20.

28. Rossoni RD, de Barros PP, do Carmo Mendonça I, Medina RP, Silva DHS, Fuchs BB, et al. The postbiotic activity of Lactobacillus paracasei 28.4 against Candida auris. Frontiers in cellular and infection microbiology. 2020;10.

29. Teame T, Wang A, Xie M, Zhang Z, Yang Y, Ding Q, et al. Paraprobiotics and postbiotics of probiotic Lactobacilli, their positive effects on the host and action mechanisms: A review. Frontiers in nutrition. 2020;7.

30. Ansari F, Pourjafar H. Nondairy Foods as Potential Carriers of Probiotic Bacteria and Postbiotics. Probiotic Bacteria and Postbiotic Metabolites: Role in Animal and Human Health. 2021:351-73.

31. Jakobsen L, Maldonado-Gómez MX, Sundekilde UK, Andersen HJ, Nielsen DS, Bertram HC. Metabolic Effects of Bovine Milk Oligosaccharides on Selected Commensals of the Infant MicrobiomeCommensalism and Postbiotic Effects. Metabolites. 2020;10(4):167.

32. Patil S, Sawant S, Hauff K, Hampp G. Validated postbiotic screening confirms presence of physiologically-active metabolites, such as short-chain fatty acids, amino acids and vitamins in Hylak ${ }^{\circledR}$ Forte. Probiotics and antimicrobial proteins. 2019;11(4):1124-31.

33. Schmalle V, Lorentz A. Role of the microbiota in circadian rhythms of the host. Chronobiology international. 2020;37(3):301-10.

34. Mantziari A, Salminen S, Szajewska H, Malagón-Rojas JN. Postbiotics against pathogens commonly involved in pediatric infectious diseases. Microorganisms. 2020;8(10):1510. 
35. Schierack P, Rödiger S, Kuhl C, Hiemann R, Roggenbuck D, Li G, et al. Porcine E. coli: virulenceassociated genes, resistance genes and adhesion and probiotic activity tested by a new screening method. PLoS One. 2013;8(4):e59242.

36. Humam AM, Loh TC, Foo HL, Izuddin WI, Awad EA, Idrus Z, et al. Dietary supplementation of postbiotics mitigates adverse impacts of heat stress on antioxidant enzyme activity, total antioxidant, lipid peroxidation, physiological stress indicators, lipid profile and meat quality in broilers. Animals. 2020;10(6):982.

37. Karimi R, Sohrabvandi S, Mortazavian A. Sensory characteristics of probiotic cheese. Comprehensive Reviews in Food Science and Food Safety. 2012;11(5):437-52.

38. Abdel-Hamid M, Romeih E, Huang Z, Enomoto T, Huang L, Li L. Bioactive properties of probiotic setyogurt supplemented with Siraitia grosvenorii fruit extract. Food chemistry. 2020;303:125400.

\section{Figures}
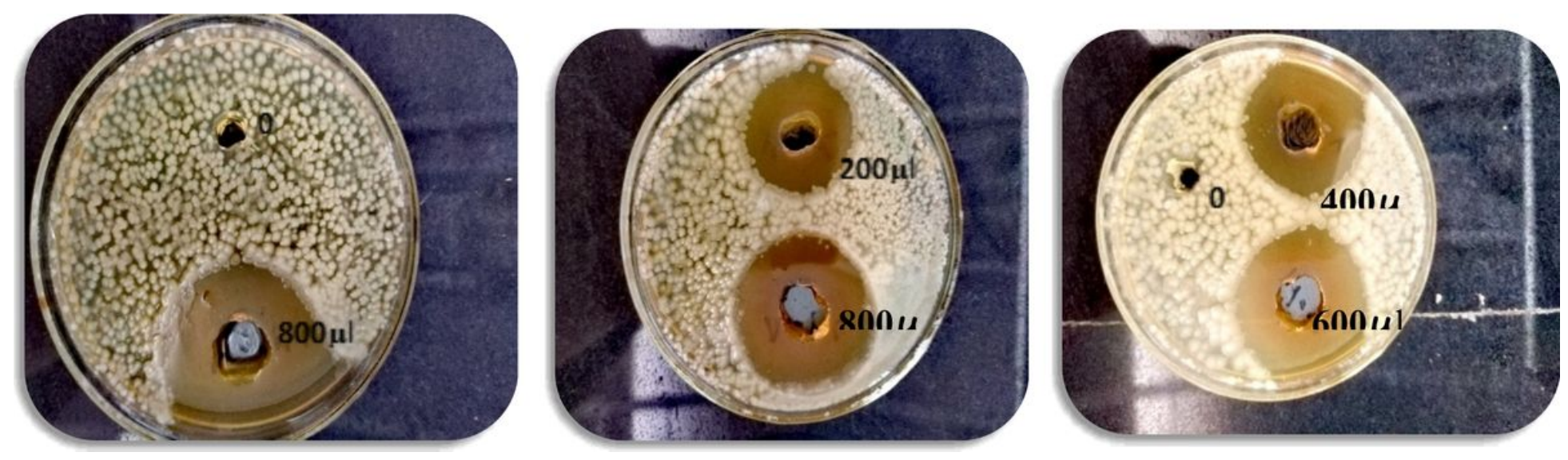

Figure 1

Antimicrobial effects of postbiotic extract (supernatant) of $L$. casei at different concentrations against $E$. coli by well method. 


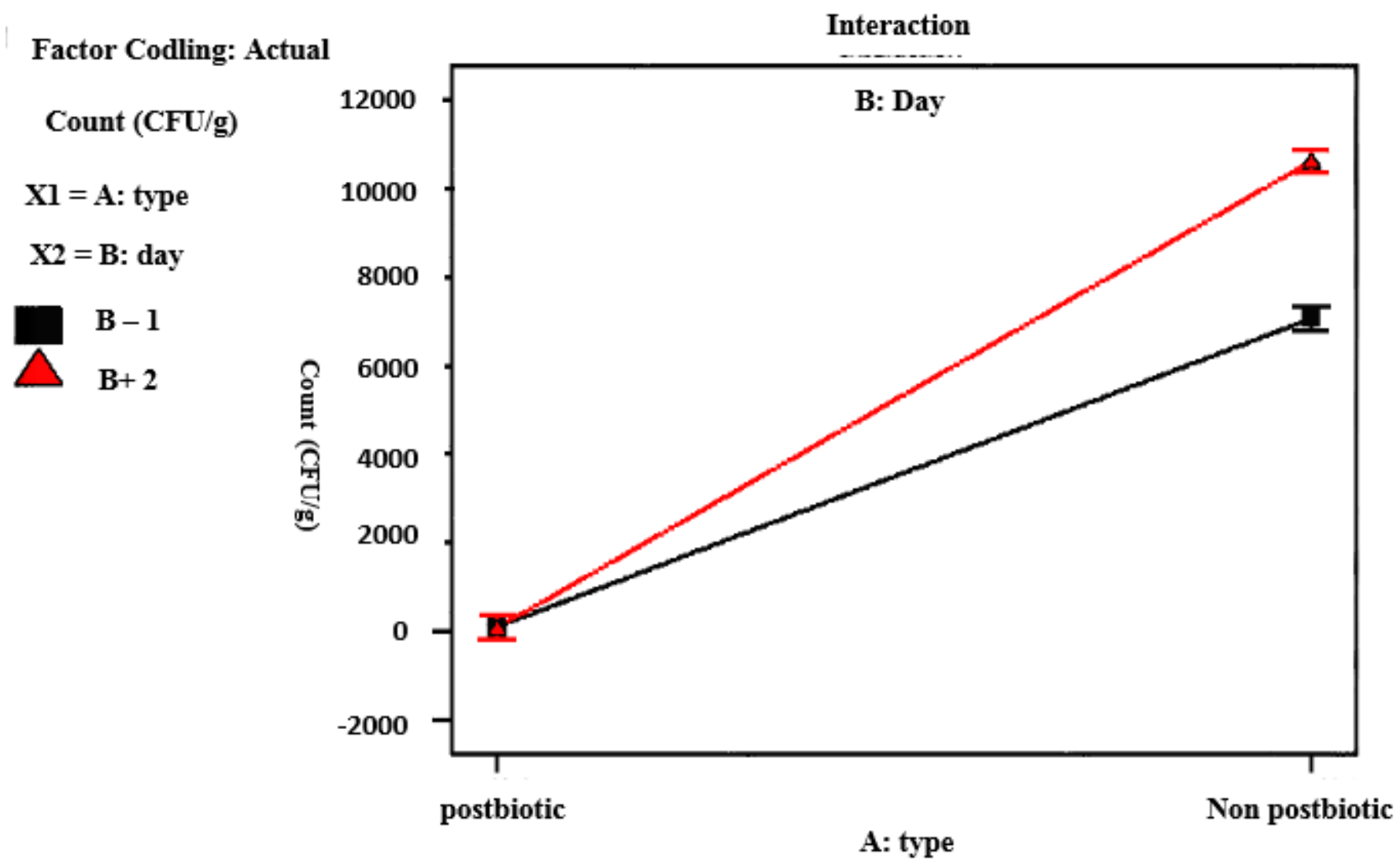

Figure 2

Evaluation of the effect of milk containing postbiotic against $E$. coli and milk without postbiotic against E. coli during storage. 

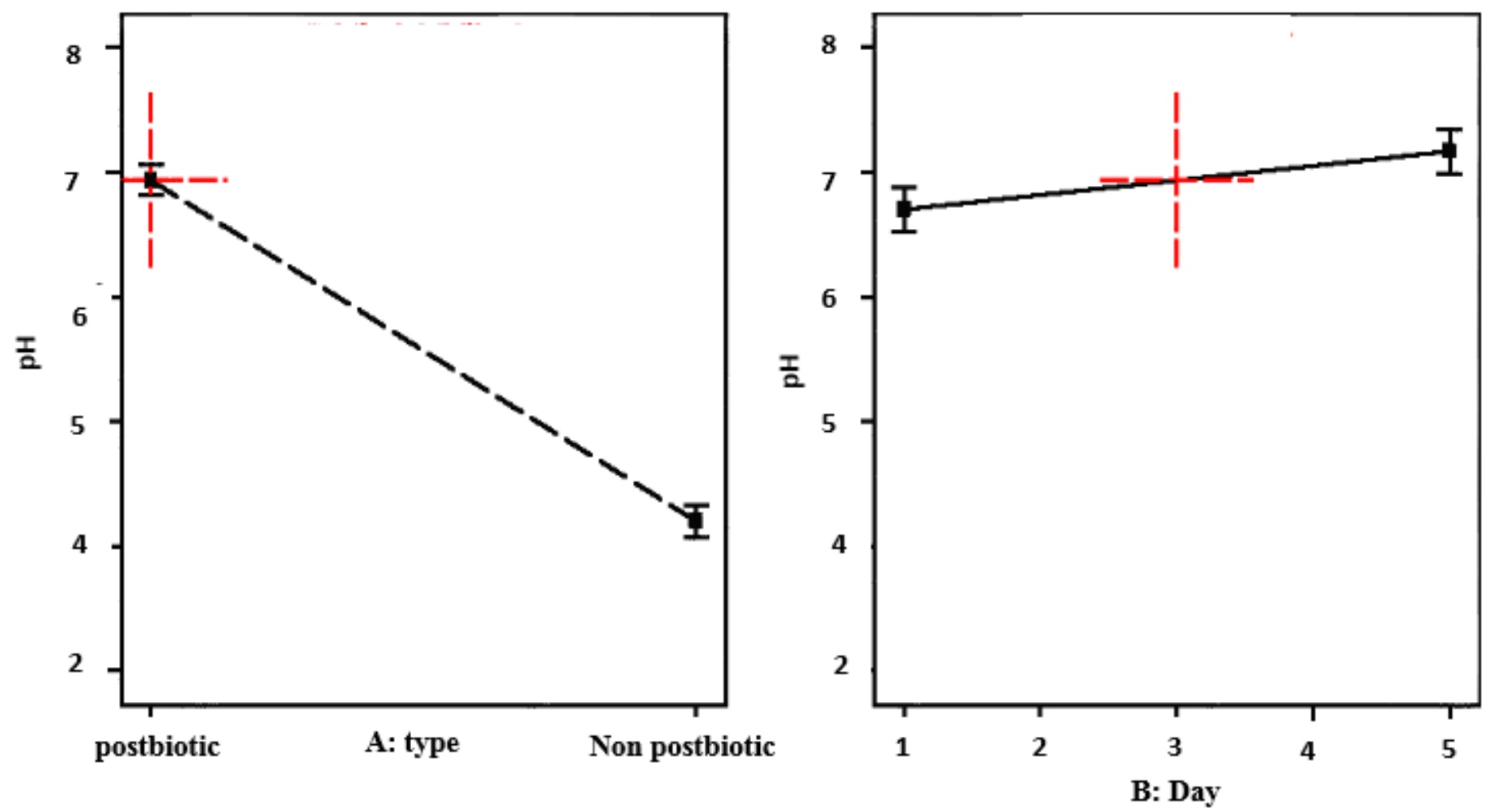

Figure 3

A: $\mathrm{pH}$ changes in milk containing postbiotic and E. coli. B: $\mathrm{pH}$ changes in milk without postbiotic and only E. coli. 